\title{
Constraints in culture-based fisheries of Sri Lanka and strategies for future development
}

\author{
W.M.H. Kelum Wijenayake ${ }^{1}$, M.M.M. Najim ${ }^{2}$ and Upali S Amarasinghe ${ }^{2 *}$ \\ ${ }^{I}$ Department of Aquaculture and Fisheries, Faculty of Livestock Fisheries \& Nutrition, Wayamba \\ University of Sri Lanka, Makandura, Gonawila 60170, Sri Lanka \\ ${ }^{2}$ Department of Zoology and Environmental Management, University of Kelaniya, Kelaniya \\ 11600, Sri Lanka \\ *Corresponding author (zoousa @kln.ac.lk)
}

ORCID ID: https://orcid.org/0000-0002-0465-6950

Received : 05.05.2021 Revised : 13.06.2021 Accepted : 17.06.2021 Online: 15.09.2021

\begin{abstract}
In the fisheries sector, fisheries enhancement through culture-based fisheries (CBF) has been recognized as an environmentally friendly approach, which is bound to contribute to increasing food fish production, especially in developing countries. Through concerted efforts, Sri Lanka achieved considerable success in CBF development in small village reservoirs in the country. However, there are some constraints to achieve the full potential in the development of CBF in Sri Lankan inland waters, which require certain interventions. Despite the availability of a magnitude of small village reservoirs in the country, the full potential of utilization of these water bodies is not achieved mainly due to the inadequacy of stocking material at the correct time under the present strategy of fish fingerling production for stocking reservoirs. It is therefore imperative that effective intervention be in place for the establishment of backyard hatcheries using simple technologies to the self-help community groups in the rural areas. The CBF strategies in non-perennial reservoirs of the country are essentially dependent on the water availability in reservoirs following monsoonal rainfall patterns. Due to anomalies in monsoonal rainfall patterns under climate change scenarios, water availability in non-perennial reservoirs in the dry zone of Sri Lanka for CBF development is rather unpredictable. As such, there is a potential risk that the rural groups engaged in fry-to-fingerling production face the difficulty of selling fish fingerlings to CBF farming groups when the non-perennial reservoirs are not filled due to insufficient monsoonal rains. An alternative strategy to link fingerling-producing community groups with the agricultural farming communities in minor perennial reservoirs should be in place to prevent such potential financial losses of fingerling producers.
\end{abstract}

Keywords: culture-based fisheries, fisheries enhancement, inland fisheries, polyculture of carps, reservoirs

\section{INTRODUCTION}

Demand for world food fish consumption is anticipated to reach $177 \mathrm{Mt}$ in 2027 , representing a projected share of $58 \%$, which is expected to originate from aquaculture production (OECD/FAO 2018). At the current rate of population growth and consumption, however it is difficult to envisage that the current global food system could meet this consumptive demand. Intensification of food production is therefore an alternative means to narrow down the gap between demand for food and supply. In the fisheries sector, fisheries enhancement has been recognized as an environmentally friendly approach, which is bound to contribute to increasing food fish production especially in developing countries (Lorenzen et al. 2001). Culture-based fisheries (CBF) development is an underutilized opportunity in fisheries enhancement (De Silva 2003), and through concerted efforts, Sri Lanka achieved considerable success in CBF development in small village reservoirs in the country (Amarasinghe and Nguyen 2010). The CBF development in Sri Lanka was initiated as part of the national fisheries development strategy in the 1980s (Thayaparan 1982), to utilize non-perennial village reservoirs ranging in size from a few ha to about 50 ha. Most 
of these small, non-perennial village reservoirs almost completely dry off during SeptemberNovember every year, so that water is available for 7-9 months following inter-monsoonal rains during the December-January period. However, CBF development did not sustain due to the absence of scientifically based criteria for the selection of suitable water bodies for CBF and insufficiency of scientific planning (De Silva 1988). In the recent past, under a research and development project funded by the Australian Centre for International Agricultural Research (Amarasinghe and Wijenayake 2015), and through a development project funded by Asian Development Bank (ADB 2011), many initiatives have been realized to identify and implement scientifically defined approaches for CBF development. However, there are some constraints to achieve the full potential in the development of CBF in Sri Lankan inland waters, which require certain interventions. In the present paper, CBF strategies of inland reservoirs in Sri Lanka are reviewed to highlight constraints to further development and to identifying future development perspectives in this aquaculture sector.

\section{CBF STRATEGIES}

Sri Lanka is endowed with a magnitude of reservoirs, a cumulative extent of which is around 206,000 ha (Figure 1; Jayasinghe and Amarasinghe 2018) having a reservoir density of about 3.1 ha for every $\mathrm{km}^{2}$ of the island. The majority of these extant reservoirs are small village reservoirs numbering $12,000-15,000$. They were constructed in the past in undulating landscapes of the country to store rainwater during the inter-monsoonal rainy season in November-January for subsequent use to irrigate paddy cultivation (Ulluwishewa 1995; Panabokke 2001; Geekiyanage and Pushpakumara 2013). Most of these reservoirs dry up almost entirely during the dry season in August-October. Utilization of them for $\mathrm{CBF}$ development should therefore be planned essentially depending on the inter-monsoonal rains. In Sri Lanka, major species that are used for CBF in inland reservoirs are Chinese and Indian major carps due to the reason that they grow to marketable size within the limited period (generally $<9$ months) of water availability in non-perennial reservoirs. Furthermore, relatively less sophisticated hatchery techniques for their induced breeding favour the use of these fish species for CBF. Due to climatic factors influencing water availability in nonperennial reservoirs, it is necessary to make fingerlings available for stocking reservoirs at the correct time. Consequently, the strategy should involve correct timing of fry-to-fingerling rearing, and induced breeding of Chinese and Indian major carps in the hatcheries (Figure 2). It is also a fact that gonad maturation of brood-stock of Chinese and Indian major carps is also linked to seasonal rainfall patterns (Winfield and Nelson 1991).

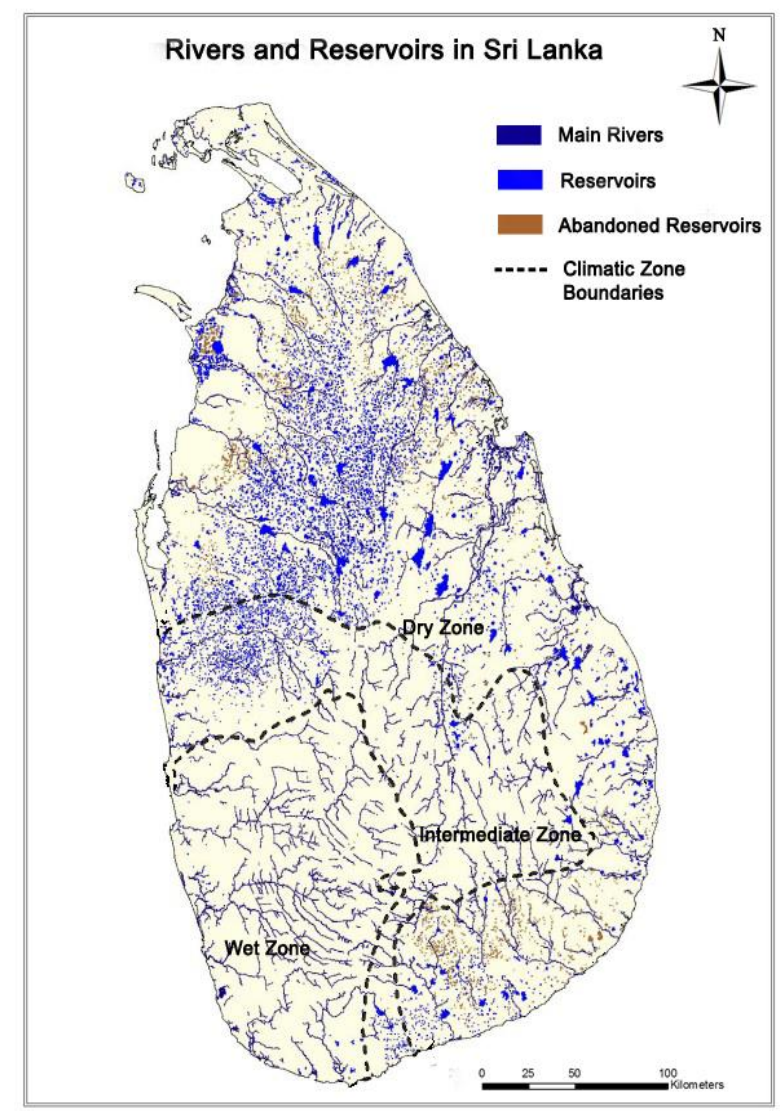

Fig 1 Distribution of rivers and reservoirs in Sri Lanka. (Source: Jayasinghe and Amarasinghe 2018).

\section{CBF AS A SOCIO-ECOLOGICAL SYSTEM}

In Sri Lanka, CBF development is essentially centered in inland reservoirs, which, based on the size, can be broadly classified as major (>800 ha), medium (200-800 ha), and minor ( $<200$ ha) reservoirs. As most of these reservoirs are primarily constructed for irrigating agricultural lands, CBF development is a secondary use. Most of the rural communities associated with these reservoirs 
W.M.H.K. Wijenayake et al.

(especially in medium and minor reservoirs) are agricultural farmers with little or no experience in fishing. Hence, for the effective introduction of CBF to a particular reservoir, in addition to the biological and ecological characteristics of the water body, socio-economic factors of rural communities should be taken into consideration. As such, CBF development in Sri Lankan reservoirs should be viewed through a socio-ecological approach (Amarasinghe and Nguyen 2010; Wijenayake et al. 2016). It must also be noted that as ownership of the stocked fish is generally vested to rural community groups, CBF comes under the realm of aquaculture (De Silva 2003).

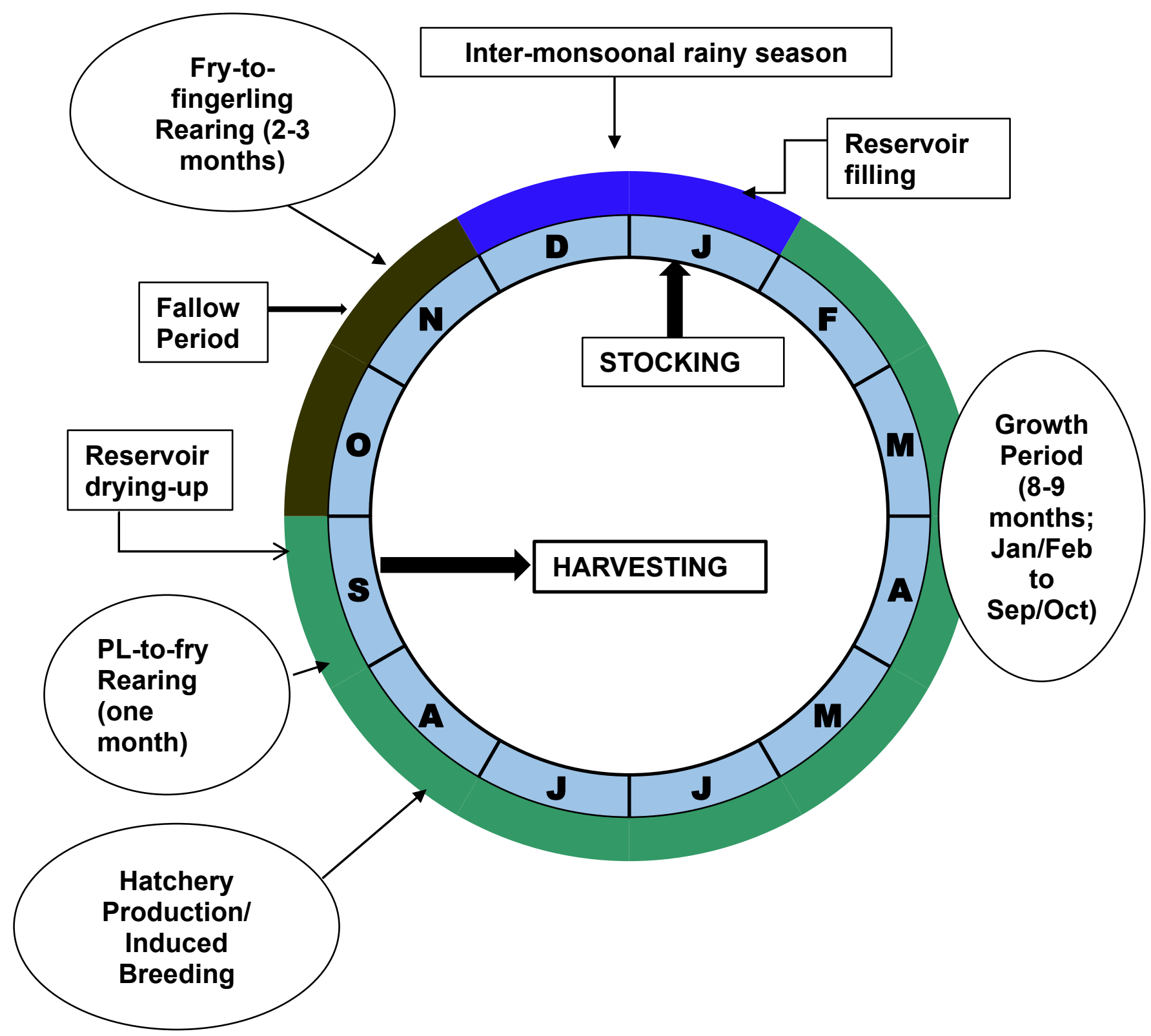

Fig 2 Ideal CBF calendar for non-perennial reservoirs in Sri Lanka 


\section{CRITERIA FOR SELECTION OF RESERVOIRS FOR CBF DEVELOPMENT}

\section{Early approaches}

In the early 1980 s when CBF strategies were introduced as part of the national inland fisheries development strategy (Thayaparan 1982), stocking of hatchery-reared Chinese and Indian major carps was performed only in non-perennial reservoirs. The main reason for using only non-perennial reservoirs for the purpose was that they were proven to be biologically productive (Mendis 1965, 1977). As such, the main criteria for evaluating the suitability of individual non-perennial reservoirs were based on their physical characteristics. Accordingly, reservoirs bearing the following physical characteristics were selected.

- Easy access to the reservoir;

- Based on the early records on water level fluctuations in the reservoirs, maintained at the Agrarian Development Department, reservoirs having a water retention period of over six months;

- Absence of impediments for fishing with an encircling net.

However, the approach adopted by the fisheries authorities at that time was essentially a 'top-down control" and virtually, there was no community consultation. Also, apart from the physical characteristics of water bodies mentioned above, no biological and sociological characteristic pertinent to CBF were taken into consideration for selecting suitable reservoirs. De Silva (1988) however, correctly predicted that as the approach adopted by the fisheries authorities has inherent weaknesses, the CBF in non-perennial reservoirs would not sustain unless a more holistic approach would be adopted taking into account biological and socioeconomic factors as well as policy-related aspects.

\section{Recent efforts for the selection of suitable reservoirs for $\mathrm{CBF}$ development}

\section{Limnological aspects}

Under a R \& D project funded by the Australian Centre for Agricultural Research, a comprehensive study was carried out on the development of a better practice approach for CBF development in non- perennial reservoirs. Jayasinghe et al. (2005) determined Carlson's trophic state index (TSI) in non-perennial reservoirs using the following three definitions of TSI presented by Carlson (1977).

TSI $(\mathrm{SD})=60-14.41 \mathrm{ln}$ Secchi disk (metres)

TSI $(\mathrm{Chl})=9.81 \mathrm{ln}$ chlorophyll-a $\left(\mathrm{mg} / \mathrm{m}^{3}\right)+30.6$

TSI $(\mathrm{TP})=14.42 \mathrm{ln}$ total phosphorus $\left(\mathrm{mg} / \mathrm{m}^{3}\right)+4.15$ Jayasinghe et al. (2005) observed that in nonperennial reservoirs of Sri Lanka TSI $(\mathrm{TP})=$ TST (SD) > TSI (SD) showing non-algal particles dominate light attenuation. Jayasinghe et al. (2005) and Wijenayake et al. (2014) also showed that CBF yields in non-perennial reservoirs of Sri Lanka were positively correlated to chlorophyll-a content. Furthermore, the ratio of forest cover plus scrubland cover in the catchment area to reservoir extent was also found to be significantly related to the chlorophyll-a content and the CBF yield (Wijenayake et al. 2014).

In non-perennial reservoirs with similar trophic characteristics, CBF yield could be predicted from the shoreline/reservoir area ratio (Jayasinghe et al. 2006). Cattle and water buffalo rearing is a common lifestyle in rural Sri Lanka, particularly in the dry zone areas. In the dry zone of Sri Lanka, each village is bestowed with a small irrigation reservoir, the drawdown area of which is waded by cattle for grazing. Also, buffaloes dip into the remaining water puddles in the reservoir. As a result, nutrients get accumulated through cow dung in the drawdown areas and water spread of reservoirs due to cattle and buffaloes wading into these reservoirs. Cattle and water buffalo densities (BD) were found to be significantly correlated to the biological productivity-related parameters such as chlorophyll-a content (Jayasinghe et al. 2018). Fish yield was also significantly correlated with BD the relationship being, $\mathrm{FY}=4.758 \mathrm{BD}+242.740(\mathrm{n}=$ $\left.33 ; \mathrm{R}^{2}=0.345 ; \mathrm{p}<0.001\right)$. Information about cattle and water buffalo density in villages is given in resource profiles of divisional secretariats. As such, for CBF management purposes, it is practicable to use data on cattle and water buffalo density rather than measuring chlorophyll-a content of the water for which technical skills and lab facilities are necessary. Consequently, it is important to take into consideration factors such as grazing cattle and buffalo density in preparing management strategies for culture-based fisheries in small village reservoirs. 
W.M.H.K. Wijenayake et al.

\section{Predatory pressure}

All village reservoirs do not completely dry up during the dry season. In such minor perennial reservoirs, carnivorous fish species such as Channa striata, Glossogobius giuris are drawn from the associated river basins, making stocked fish fingerlings vulnerable to predatory pressure (Wijenayake et al. 2005). De Silva (1988) suggested that this could be prevented by stocking large-sized $(>10 \mathrm{~cm})$ fingerlings, which are not vulnerable to predatory pressure.

\section{Species combination and stocking density}

As CBF strategies practiced in small village reservoirs are aimed at achieving higher fish production per unit area, fingerlings of species capable of optimal utilization of food resources in the water body are stocked, similar to polyculture systems (Bardach et al. 1972). The species combination used was $30 \%$ common carp and mrigal, $30 \%$ bighead carp/catla; $30 \%$ rohu, and $10 \%$ Nile tilapia/freshwater prawn (Wijenayake et al. 2005).

As extents of non-perennial reservoirs vary from the value corresponding to full capacity during the rainy season to gradual shrinking almost to zero during the dry season, the effective area for CBF planning (i.e., to estimate stocking density and $\mathrm{CBF}$ yield) is considered as $50 \%$ of the area at the full supply level. Wijenayake et al. (2005) have found that the relationship between stocking density (SD) and CBF yield conformed to second-order curve, similar to those reported in Bangladesh (Hasan and Middendrop 1998) and India (Sugunan and Katiha 2004). Accordingly, the optimal SD in small village reservoirs of Sri Lanka was determined to be about 3,500 fingerlings per ha (Wijenayake et al. 2005).

\section{Socio-economic criteria for reservoir selection}

CBF activities in small village reservoirs are essentially communal activities involving agricultural farming communities. Under the legal provisions of Agrarian Development Act No. 46 of 2000 through which farmers' organizations (FOs) are empowered to make decisions on agriculturerelated economic activities, the National Aquaculture Development Authority of Sri Lanka (NAqDA) has introduced a strategy for social mobilization in FOs for CBF development. These involved establishment of Aquaculture Management Committees (AqMCs), which are vested by FOs to carry out $\mathrm{CBF}$ activities in reservoirs. The benefit-sharing mechanism is through an agreement between AqMC and FO. In many instances a levy of about $5 \%$ of the net profit is paid to the FO. As part of the aquaculture extension activities, NAqDA guides FOs to prepare an entrepreneurship plan for CBF. As this initiative essentially consists of features of participatory rural appraisal (PRA) methodology, where needs and aspirations of end-users are taken into consideration in the development planning process, the members of FO are motivated to adopt CBF as part of their contribution to the rural economy.

According to a socio-economic analysis of agricultural farming communities in village reservoirs where $\mathrm{CBF}$ was carried out, communities with small group sizes in AqMCs with satisfactory participation in group activities and those belong to same caste exhibited high 'willingness to pay' for CBF activities (Kularatne et al. 2009). Further, Kularatne et al. (2009) reported that social mobilization of rural communities to adopt CBF in village reservoirs would be easier when there are leadership qualities of members of AqMCs, and good education levels among members of communities.

\section{Multiple-criteria decision making approach}

As it is evident from the above, the selection of suitable reservoirs for CBF development should be based on several criteria, such as biological productivity, catchment land-use characteristics influencing nutrient enrichment in reservoirs, and socioeconomic factors. Hence, multiple-criteria decision making (MCDM) approaches are found to be important for the purpose. MCDM evaluates multiple conflicting criteria in decision making. Analytic Hierarchical Process (AHP; Saaty 1977) is an MCDM approach that equates sets of heterogeneous criteria into a common denominator. Accordingly, Wijenayake et al. (2016) have employed AHP as a tool to select non-perennial reservoirs suitable for CBF development, based on three main criteria (reservoir productivity, catchment characteristics, and socio-economic factors) that influence $\mathrm{CBF}$ yield. 
De Silva et al. (2006) presented a better practice approach considering technical aspects and socioeconomic aspects which facilitates the selection of technically and socioeconomically feasible reservoirs for CBF development (Figure 3). The order of each step in the dichotomous flowchart presented in Figure 3, can vary with users, but it represents all technical and socioeconomic aspects that should be considered for selecting reservoirs for $\mathrm{CBF}$ development.

\section{CONSTRAINTS TO DEVELOPMENT}

\section{Technical constraints}

There are several mini-nurseries established by community-based organizations (CBOs) in many parts of the country (Anon. 2006). In these mininurseries, fry-to-fingerling rearing is carried out and the CBOs purchase fry from state-owned fish hatcheries. It can be seen that institutional linkages are essential among state-owned hatcheries, community-based organizations (CBOs) maintaining mini-nurseries for fry-to-fingerling rearing, and agricultural farmers' organizations in villages who are engaged in $\mathrm{CBF}$. The driving forces for $\mathrm{CBF}$ strategies in reservoirs are essentially fingerling production by community groups engaged in fry-to-fingerling rearing, and the link between fingerling rearing groups and $\mathrm{CBF}$ communities should be established by effective extension mechanism in the state fisheries and aquaculture sector (Figure 4).

When the monthly fry production figures in three state-owned fish hatcheries are considered (Figure 5), August-September is not the ideal period for induced breeding. However, according to an ideal calendar of CBF (Figure 2), to make available of fish fingerlings for stocking in small nonperennial reservoirs, fry-to-fingerling rearing in mini-nurseries should be carried out from September to November. In the community-based mini nurseries where fry-to-fingerling rearing is carried out, one culture cycle generally lasts for about 60 days. As such, fingerlings are available for sale in these mini nurseries during the period when they are not required for stocking in non-perennial reservoirs, as illustrated in Figure 2. The fish fingerlings that are produced in the mini nurseries during the seasons when they are not needed for stocking in non-perennial reservoirs, alternative means of stocking in other aquaculture systems should be considered to make sure timely demand for fingerlings produced by the community groups. Pushpalatha and Chandrasoma (2010) have shown that $\mathrm{CBF}$ efforts in minor perennial reservoirs extents of which ranged from 52 ha to 236 ha, resulted in a significant increase in fish yield. As such, $\mathrm{CBF}$ development in minor perennial reservoirs $(<200 \mathrm{ha})$ can also be considered as an additional means for increasing inland fisheries production in Sri Lanka.

Of the different categories of reservoirs, small non-perennial reservoirs are the most suitable water bodies for the development of $\mathrm{CBF}$ for several reasons such as high biological productivity, and the existence of legal provisions in the Agrarian Development Act No. 46 of 2000 (Anon. 2000) and Amended Act No. 46 of 2011 (Anon. 2011) to incorporate fisheries and aquaculture aspects in reservoir management, the willingness of farmer organizations (i.e., agricultural farmers) to adopt CBF strategies and proven economic viability of $\mathrm{CBF}$ in small village reservoirs (Amarasinghe and Nguyen 2010; Kularatne et al. 2018). There are 12,000-15,000 small irrigation reservoirs in Sri Lanka, most of which are highly productive nonperennial reservoirs having potential for $\mathrm{CBF}$ development. However, the number of small village reservoirs that are stocked annually was within the range of 300-450 reservoirs; http://www.naqda.gov.lk/statistics/Stocking-offish-fingerlings-and-freshwater-prawn-postlarvae/. Due to the insufficiency of fish fingerlings to stock in different types of inland water bodies, when inland water bodies of one type is intensively stocked, other types of water bodies are not sufficiently stocked (Figure 6). As such, scarcity of fingerlings is a major technical constraint to the further development of CBF. Except for giant freshwater prawn (Macrobrachium rosenbergii), which is produced on small-scale in a private hatchery, all finfish species that are used for CBF are captively bred in state-owned aquaculture development centres (ADCs). Due to their limited hatchery and rearing facilities, for sufficient fingerling production, an effective strategy should be implemented to increase fish seed production for CBF development. 
W.M.H.K. Wijenayake et al.

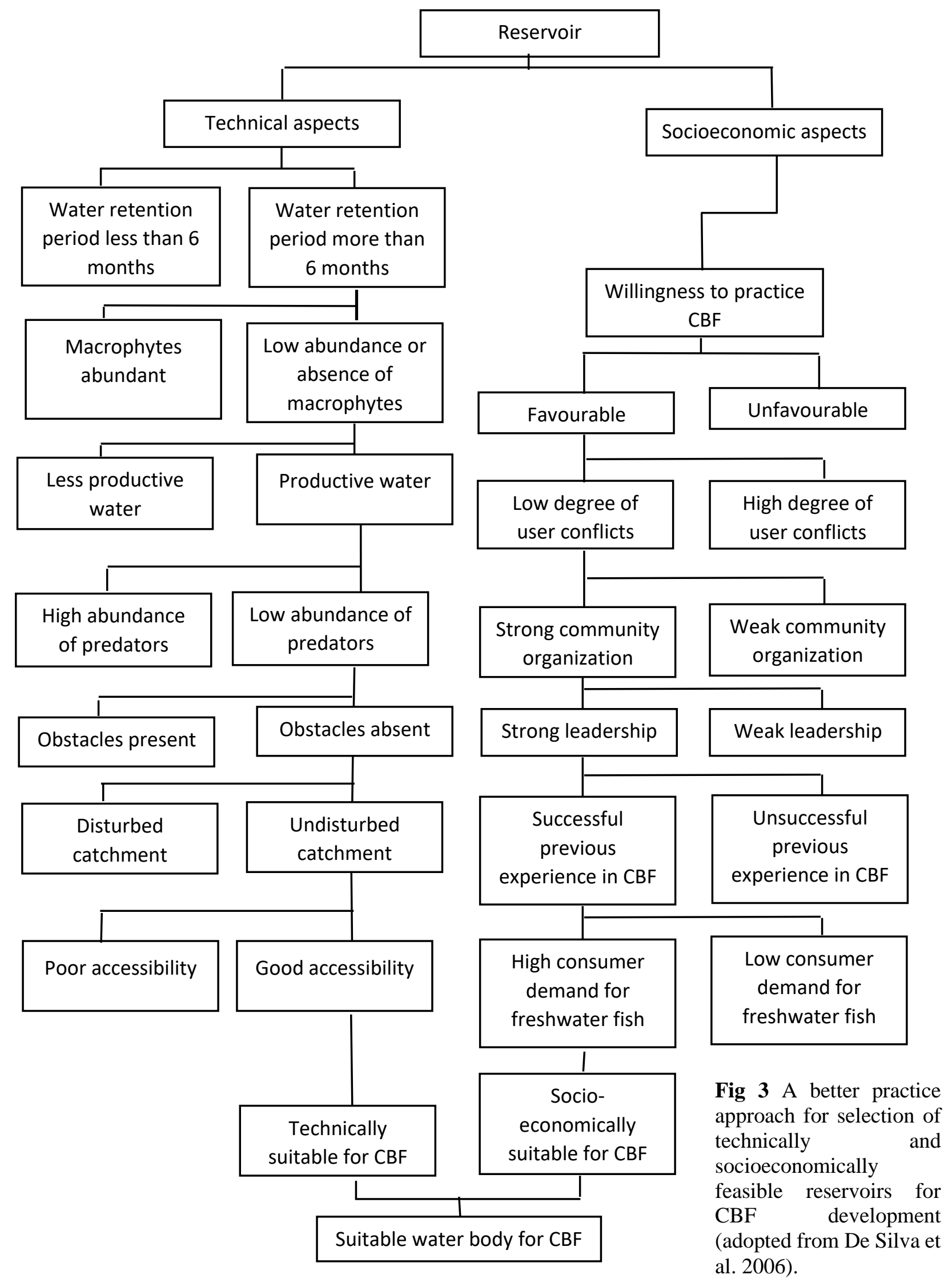




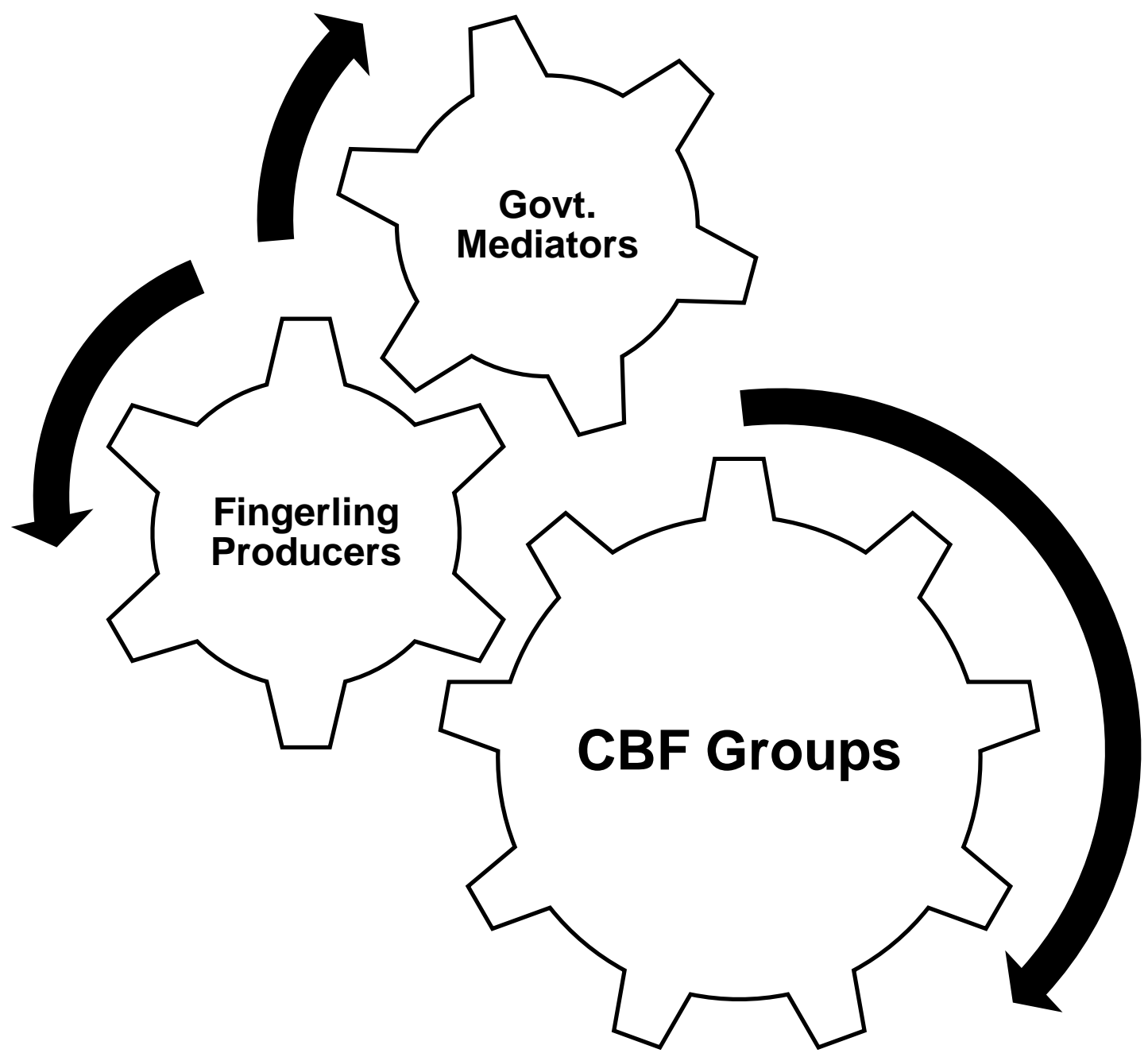

Fig 4 State and community level driving forces in the CBF strategy showing the necessity for strong coordination among different role players. 
W.M.H.K. Wijenayake et al.

\section{Fry Production}

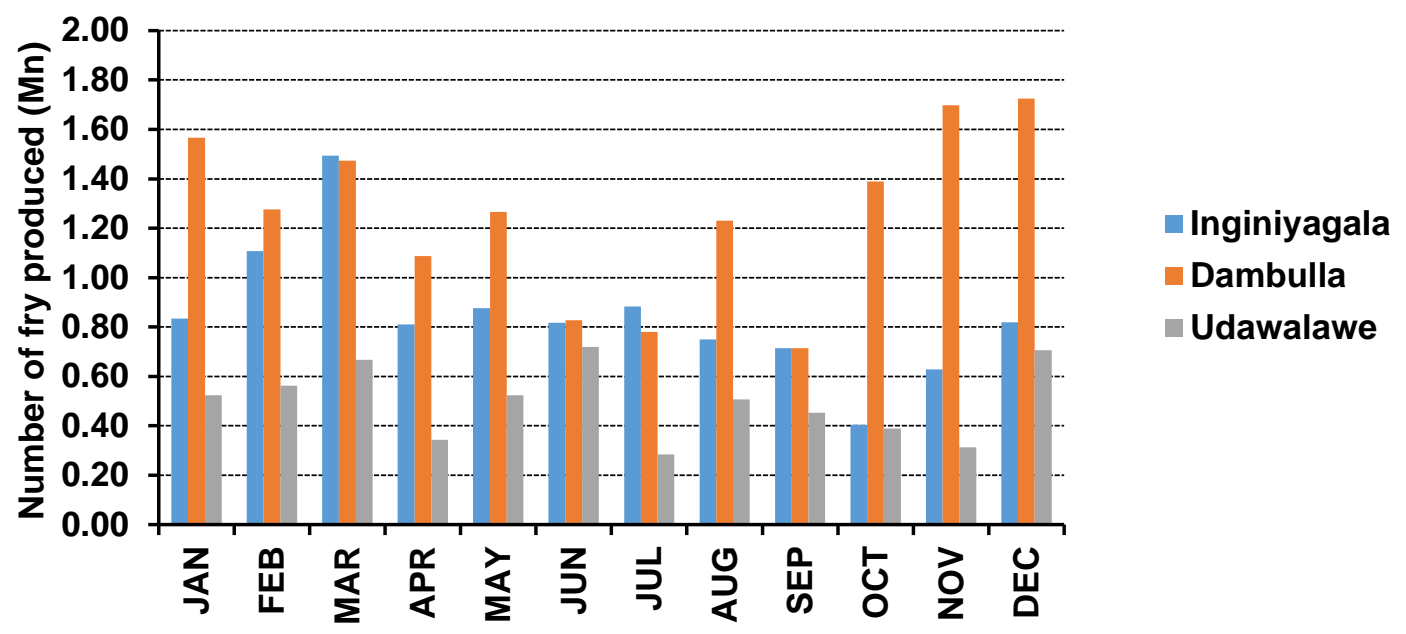

Fig 5 Monthly variation in the production of Chinese and Indian major carp fry in three state-owned hatcheries

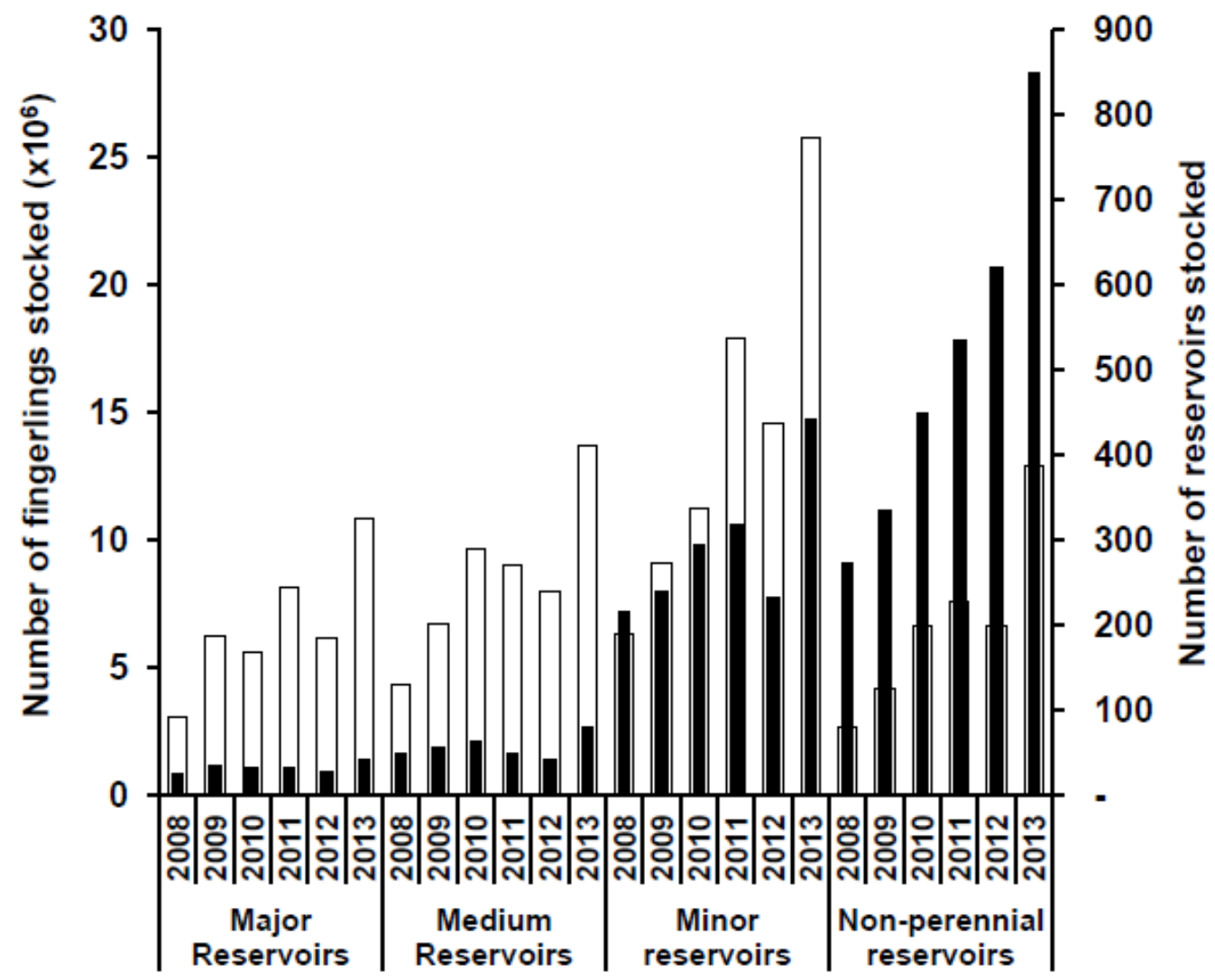

Fig 6 Number of reservoirs of different categories and number of fingerlings stocked during 2008-2013. [Adopted from Amarasinghe and Wijenayake (2015), using the data reported at http://www.fisheries.gov.lk/content.php?cnid=ststc]. White bars - Number of fingerlings stocked; Dark bars - Number of reservoirs stocked. 


\section{Environmental constraints}

Climate change impacts on fisheries and aquaculture and other food production sectors such as agriculture and livestock are often viewed in the context of long-term impacts due to global warming (https://19january2017snapshot.epa.gov/climateimpacts/climate-impacts-agriculture-and-foodsupply_html; Barange et al. 2018; Phillips and Pérez-Ramírez 2018). Spatial variation of rainfall in Sri Lanka during the wet season (OctoberFebruary) (Maha) for the baseline (1961-1990), and predicted 2050 scenarios have shown (De Silva et al. 2007) decrease in rainfall across most of the country, and increased irrigation demand for paddy cultivation that will decrease the water levels in the reservoirs quickly. Abeysekera et al. (2015) have shown that as climate change is likely to exacerbate extreme rainfall events in the future, excess soil moisture stress in rain-fed upland crops, flood damages in lowland paddy fields, and rapid drying out in cascade of reservoirs in the long run would be a serious threat to agricultural productivity in the dry zone of Sri Lanka.

CBF in non-perennial reservoirs in Sri Lanka is essentially dependent on the annual rainfall pattern in the country (Figure 2). Availability of fish fingerlings for stocking at the correct time is, therefore, a prerequisite for its sustainability.
Rearing of hatchery-reared fish up to fingerling size involves three main stages: induced breeding of major carps, rearing of post-larvae up to fry stage in hatcheries, and fry-to-fingerling rearing by rural community groups. Reliable prediction of water availability in village reservoirs is useful for planning $\mathrm{CBF}$ to make available fingerlings for stocking at the correct time. Najim et al. (2010) have made an attempt to predict water availability in village reservoirs, based on local rainfall, evaporation rates, nature and extent of the catchment, etc. using HEC-HMS 3.4 software (Fleming 2009). From this analysis it was found that the rainfall pattern was unpredictable, reduced precipitation in $1^{\text {st }}$ inter monsoon, Increased precipitation during the latter part of south-west monsoon (August-September), frequent drying-off of reservoirs, and consequently uncertainty of water availability for agriculture and aquaculture. Increased drawdown of reservoir volumes in two geographical regions of the country are shown in Figure 7. Also, an irregular pattern of water availability is evident in some reservoirs (Figure 8). In these cases, normal patterns of reservoir filling and retaining water for a reasonable period for the growth of stocked fish (8-9 months) do not prevail for adopting the ideal CBF crop calendar as depicted in Figure 2.
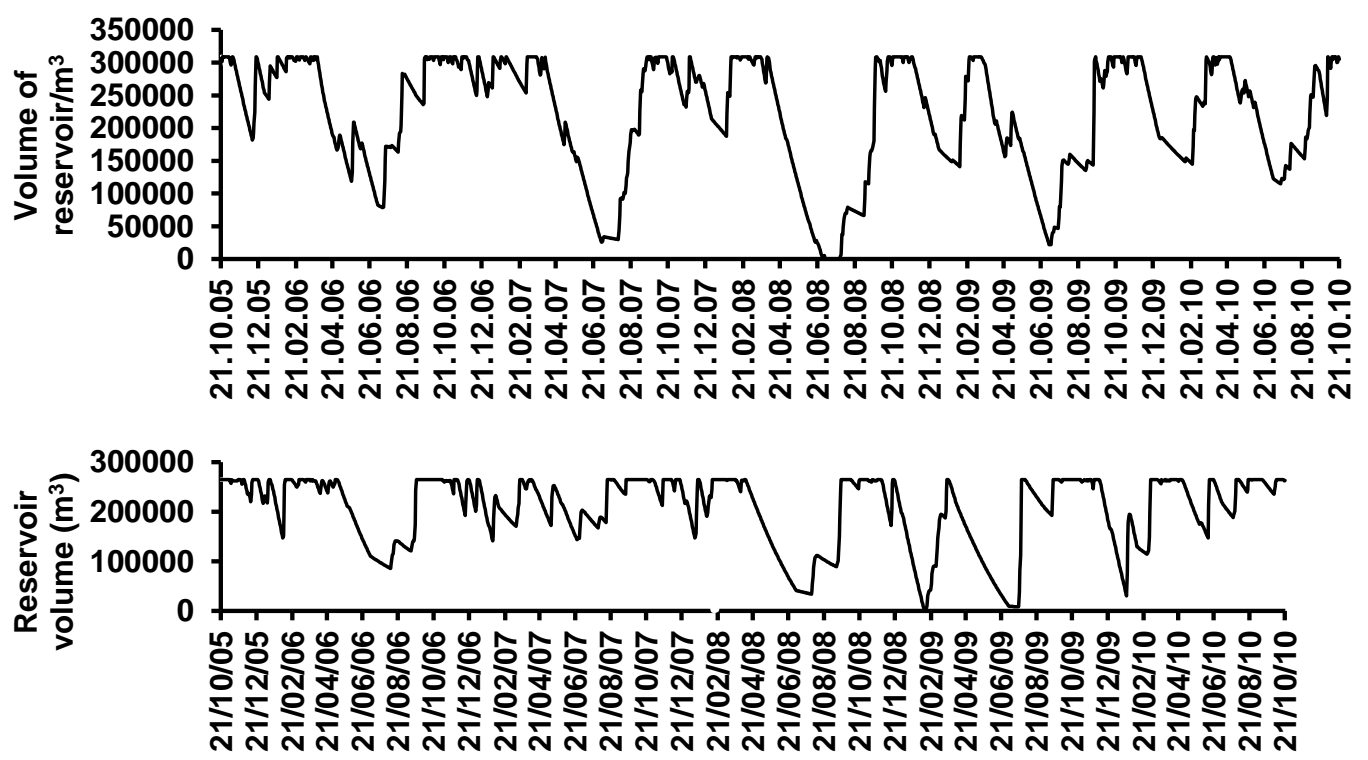

Fig 7 Increased drawdown of reservoir volume of Wewegama wewa (upper panel) in Hambantota District and Katugampolagama wewa (lower panel) in Anuradhapura District during 2005-2010 period making reservoir unsuitable for adopting ideal CBF calendar shown in Figure 2. 


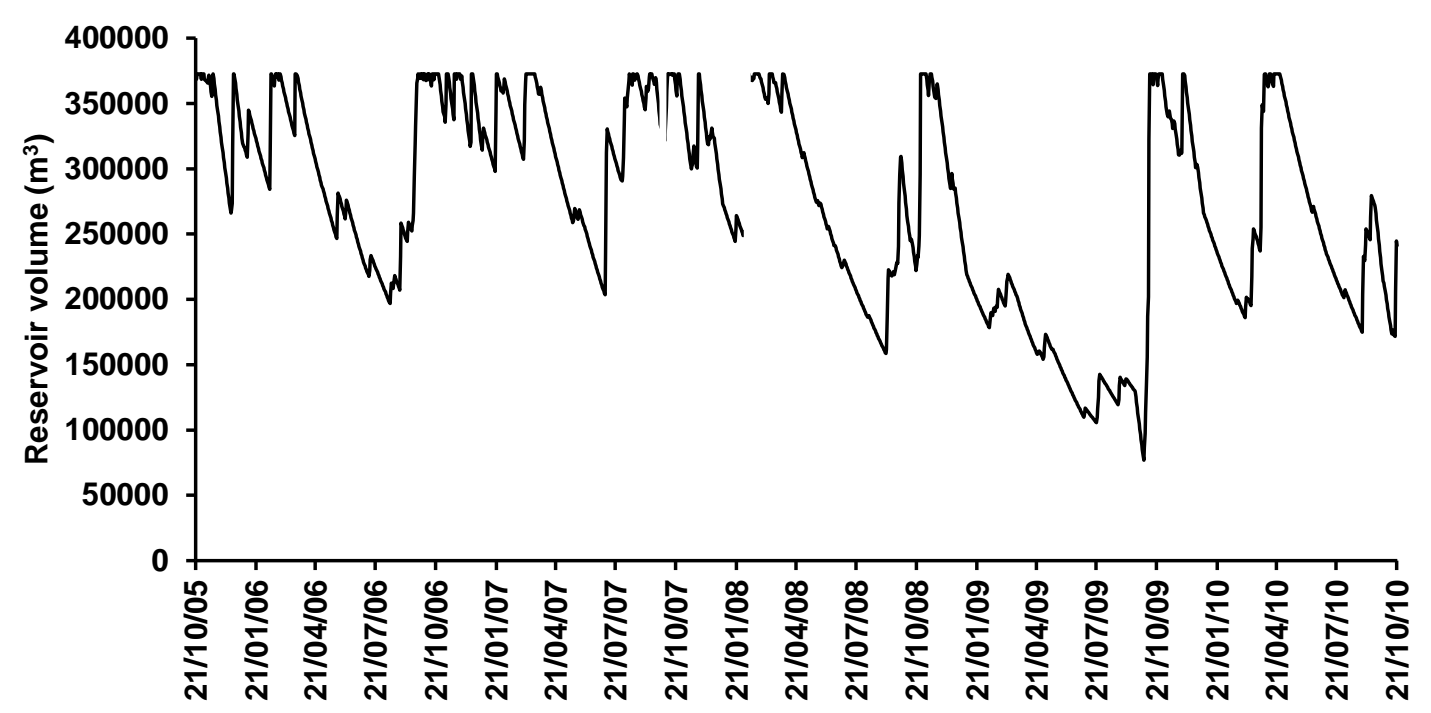

Fig 8 Changes in volume of Madagamkadawara reservoir in Hambantota District during 2005-2010 showing an irregular pattern of water availability for adopting ideal CBF crop calendar depicted in Figure 2 .

Due to the unpredictability of water availability in non-perennial reservoirs in the dry zone of Sri Lanka, the routine procedure for stocking and harvesting fish in non-perennial reservoirs (Figure 2) cannot be assured every year. This might lead to overall discouragement of community groups involved in fingerling rearing because of the lack of assurance for selling fish fingerlings to CBF groups in non-perennial reservoirs.

\section{FUTURE PERSPECTIVES}

From the present synthesis, it is evident that the scarcity of fingerlings to stock in reservoirs is one of the major technical constraints to further development of CBF in Sri Lanka. As such, the establishment of small-scale community-based hatcheries appears to be a solution to overcome this constraint. The guidelines for the establishment of backyard hatcheries for common, Chinese, and Indian carps are available (Jhingran and Pullin 1985). Mohapatra et al. (2015) reported a case study of the introduction of a portable fiber-reinforced plastic (FRP) hatchery along with technical support to a remote and inaccessible village in Odisha, India targeting women self-help groups. In this case, a poor group of women with no ownership of such assets was able to produce fish seed in a remote area. Through the government extension mechanism, an enabling environment was provided which contributed to the group having sufficient confidence for the successful operation of the hatchery.

However, under the present scenario where the number of non-perennial reservoirs stocked annually is less than $5 \%$ of the total number of reservoirs, which are potentially suitable for $\mathrm{CBF}$ development and due to the season that aquaculture development authorities allocate entire fingerling production during December-January solely for stocking non-perennial reservoirs, fingerling availability for $\mathrm{CBF}$ is not a limiting factor. However, it is obvious that at the full pace of CBF development in the country, fingerling limitation for $\mathrm{CBF}$ is inevitable. Hence, the introduction of simple hatchery technologies to rural self-help groups as practiced in in Odisha, India (Mohapatra et al. 2015) is necessary to remove the bottleneck of fingerling supply for CBF development in the country.

According to climate change scenarios, for the sustainability of CBF in village reservoirs, and improving the resilience of rural communities for climate change, alternative means of stocking fish fingerlings reared by rural communities should be 
sought (Figure 9). This is of particular importance because the marketplace for fingerlings produced in mini nurseries is needed to be ensured for the sustainability of the whole process pertaining to CBF development as illustrated in Figure 4. As Pushpalatha and Chandrasoma (2010) have shown that a significant enhancement of overall $\mathrm{CBF}$ production can be achieved through CBF in minor perennial reservoirs. Hence, harmonization of agricultural and $\mathrm{CBF}$ activities in non-perennial reservoirs as well as in minor perennial reservoirs, depending on the water availability is recommended to improve climate change adaptations of rural communities.

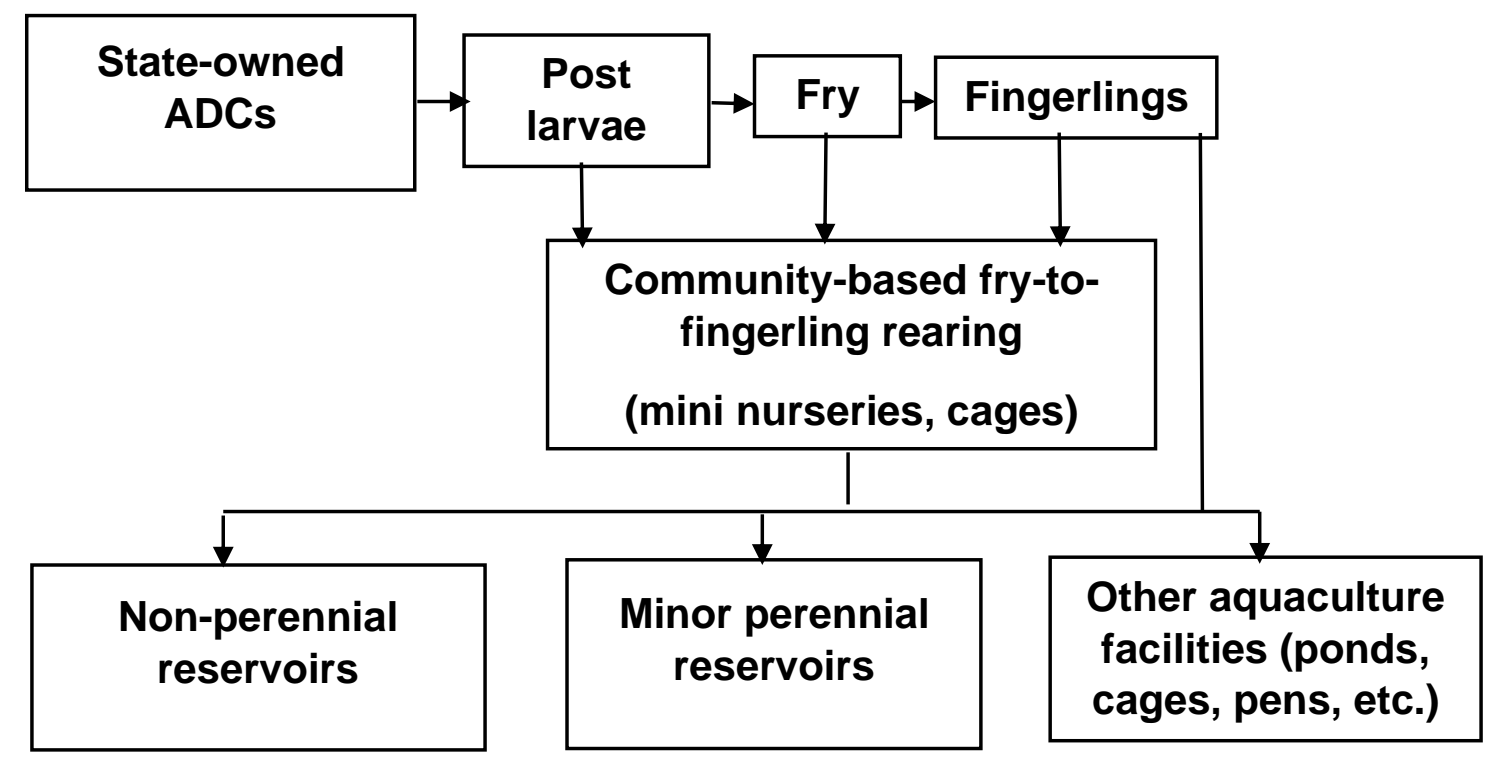

Fig 9 Alternative means of stocking of fish fingerlings reared by rural communities for CBF development.

\section{REFERENCES}

Abeysekera, A.B., B.V.R. Punyawardena \& K.H.M.S. Premalal. 2015. Recent trends of extreme positive rainfall anomalies in the dry zone of Sri Lanka. Tropical Agriculturist 163: $1-23$.

ADB. 2011. Sri Lanka: Aquatic Resource Development and Quality Improvement Project. Completion Report (Project Number: 34318). Manila: Asian Development Bank. 87 p.

Amarasinghe, U.S. \& T.T.T. Nguyen. 2010. Enhancing rural farmer income through fish production: Secondary use of water resources in Sri Lanka and elsewhere. In: De Silva, S.S. \& F.B. Davy (Eds.), Success Stories in Asian Aquaculture, pp. 103-130. Dordrecht: Springer Science. ISBN 978-90-481-3085-6 (Print) ISBN 978-90-481-3087-0 (Online) http://library.enaca.org/emerging_issues/succe ss_stories/success-stories-asian-

aquaculture.pdf

Amarasinghe, U.S. \& W.N.H.K. Wijenayake. 2015. Results of a decade of R \& D efforts on culturebased fisheries in Sri Lanka. In: De Silva, S.S., B.A. Ingram \& S. Wilkinson (Eds.), Perspectives on Culture-based Fisheries Developments in Asia, pp. 59-71. NACA Monograph Series No. 3. Bangkok: Network of Aquacuture Centres in Asia-Pacific.126p.

Anon. 2000. Agrarian Development Act No 46 of 2000. Colombo: Gazette of the Democratic Socialist Republic of Sri Lanka.

Anon. 2006. Mini nursery program. Aquaculture News. NAQDA Newsletter (SeptemberDecember 2006) 3: 1.

Anon. 2011. Agrarian Development (Amendment) Act No 46 of 2011. Colombo: Gazette of the Democratic Socialist Republic of Sri Lanka. 
W.M.H.K. Wijenayake et al.

Barange, M., T. Bahri, M.C.M. Beveridge, K.L. Cochrane, S. Funge-Smith \& F. Poulain (Eds.). 2018. Impacts of climate change on fisheries and aquaculture. Synthesis of current knowledge, adaptation and mitigation options. FAO Fisheries and Aquaculture Technical Paper No. 627, Rome: FAO. 628 p.

Bardach, J.E., J.H. Ryther \& W.O. McLarney. 1972. Aquaculture: The Farming and Husbandry of Freshwater and Marine Organisms. Chichester: Wiley-Interscience. 868 p.

Carlson, R.E. 1977. A trophic state index for lakes. Limnology and Oceanography 22: 361-369. https://doi.org/10.4319/lo.1977.22.2.0361

De Silva, C.S., E.K. Weatherhead, J.W. Knox \& J.A. Rodriguez-Diaz. 2007. Predicting the impacts of climate change: A case study of paddy irrigation water requirements in Sri Lanka. Agricultural Water Management 93: 1929. https://doi.org/10.1016/j.agwat.2007.06.003

De Silva, S.S. 1988. Reservoirs of Sri Lanka and Their Fisheries. FAO Fisheries Technical Paper 298, Rome: FAO. 128 p.

De Silva, S.S. 2003. Culture-based fisheries: an underutilised opportunity in aquaculture development. Aquaculture 221: 221-243. https://doi.org/10.1016/S0044-8486(02)006579

De Silva, S.S. 2015. Culture-based fisheries: Why, what, where, how and for whom? In: De Silva, S.S., B.A. Ingram, \& S. Wilkinson (Eds.), Perspectives on Culture-based Fisheries Developments in Asia, pp. 17-25. Bangkok: Network of Aquaculture Centres in AsiaPacific.

De Silva S.S., U.S. Amarasinghe \& T.T.T. Nguyen (Eds.). 2006. Better-practice approaches for culture-based fisheries development in Asia. ACIAR Monograph No. 120. 96 p. Canberra: Australian Centre for International Agricultural Research. ISBN 1863204571 (print), 186320 $458 \mathrm{X}$ (online).

Fleming, M.J. 2009. Hydrologic Modeling System, HEC-HMS. Quick Start Guide, Version 3.4. Davis, CA: US Army Corps Engineers, Institute for Water Resources, Hydrologic Engineering Centre. 46 p.

Geekiyanage, N. \& D.K.N.G. Pushpakumara. 2013. Ecology of ancient tank cascade systems in island Sri Lanka. Journal of Marine and Island Cultures 2(2): 93-101.

https://doi.org/10.1016/j.imic.2013.11.001

Hasan, M.R. \& H.A.J. Middendorp. 1998. Optimising stocking density of carp fingerlings through modeling of the carp yield in relation to average water transparency in enhanced fisheries in semi-closed water bodies in western Bangladesh. In: Petr. T. (Ed.), Inland Fishery Enhancements, pp. 159-168. Papers Presented at the FAO/DFID Expert Consultation on Inland Fishery Enhancements, Dhaka, Bangladesh, 7-11 April 1997. FAO Fisheries Technical Paper No. 374. Rome: FAO.

Jayasinghe, J.M.P.K. \& U.S. Amarasinghe. 2018. Inland Aquatic Resources. In: Wijeyaratne, M.J.S., A.H.M. Jayasuriya \& N.P. Wijayananda (Eds.), Natural Resources of Sri Lanka: Conditions, Trends and Prospects, pp. 327-343. Colombo: National Science Foundation of Sri Lanka. 420 p.

Jayasinghe, U.A.D., U.S. Amarasinghe \& S.S. De Silva. 2005. Trophic classification of nonperennial reservoirs utilized for the development of culture-based fisheries, Sri Lanka. International Review of Hydrobiology 90: 209-222. https://doi.org/10.1002/iroh.2004 10753

Jayasinghe, U.A.D., U.S. Amarasinghe \& S.S. De Silva. 2006. Culture-based fisheries in nonperennial reservoirs of Sri Lanka: Influence of reservoir morphometry and stocking density on yield. Fisheries Management and Ecology 13: $157-164$.

https://doi.org/10.1111/j.1365-

2400.2006.00488.x

Jayasinghe, A.D., J.A., Athula, S.S. De Silva \& U.S. Amarasinghe. 2018. Cattle and water buffalo densities wading into small village reservoirs of Sri Lanka impact on yields of the culture-based fisheries thereof. Sri Lanka Journal of Aquatic Sciences 23(1): 67-75. http://doi.org/10.4038/sljas.v23i1.7547

Jhingran, V.G. \& R.S.V. Pullin. 1985. A hatchery manual for the common, Chinese and Indian major carps. ICLARM Studies and Reviews 11, 191 p. Manila: Asian Development Bank, and Manila: International Centre for Living Aquatic Resources Management.

Kularatne, M.G., U.S. Amarasinghe, P. Wattage \& S.S. De Silva. 2009. Evaluation of community 


\section{W.M.H.K. Wijenayake et al.}

participation for the development of culturebased fisheries in village reservoirs of Sri Lanka. Aquaculture Economics and Management 13: 22-38. https://doi.org/10.1080/13657300802674914

Kularatne, M.G., S. Pascoe, C. Wilson \& T. Robinson. 2018. Efficiency of culture-based fisheries production in village irrigation systems of Sri Lanka. Aquaculture Economics and Management 23(1): 65-85.

https://doi.org/10.1080/13657305.2018.149710 4

Lorenzen, K., U.S. Amarasinghe, D.M. Bartley, J.D. Bell, M. Bilio, S.S. De Silva, C.J. Garaway, W.D. Hartman, J.M. Kapetsky, P. Laleye, J. Moreau, V.V. Sugunan \& D.B. Swar. 2001. Strategic review of enhancements and culturebased fisheries. In: Subasinghe, R.P., P. Bueno, M.J. Phillips, C. Hough, S.E. McGladdery \& J.R. Arthur (Eds.), Aquaculture in the Third Millennium. pp. 221-237. Technical Proceedings of the Conference on Aquaculture in the Third Millennium. Bangkok, 20-25 February 2000. Bangkok: NACA and Rome: FAO.

Mendis, A.S. 1965. A preliminary survey of 21 Ceylon lakes, 2: Limnology and fish production potential. Bulletin of Fisheries Research Station, Ceylon 16: 7-16.

Mendis, A.S. 1977. The role of man-made lakes in the advancement of fisheries in Sri Lanka. Proceedings of the Indo Pacific Fisheries Commission 17(3): 247-254.

Mohapatra, B.C., N.K. Barik, S.K. Mahanta, H. Sahu, B. Mishra \& D. Majhi. 2015. Small-scale carp seed production through portable FRP hatchery at Khanguri, Odisha: A case of technology transfer in remote and inaccessible village. Aquaculture Asia, 20(1), JanuaryMarch 2015, 21-27. Network of Aquaculture Centres in Asia-Pacific, Bangkok, Thailand.

Najim, M.M.M., W.M.H.K. Wijenayake, S.S. De Silva \& U.S. Amarasinghe. 2010. Impact of climate change on culture-based fisheries of Sri Lanka: possible adaptations of communities. In: Proceedings of the Second National Symposium on Disaster Risk Reduction and Climate Change Adaptation, 13-14 October 2010. Colombo: Sri Lanka Foundation Institute.

Panabokke, C.R. 2001. The nature and properties of small tank systems of the dry zone and their sustainable production thresholds. In: Gunasena, H.P.M. (Ed.), Food Security and Small Tank Systems in Sri Lanka. pp. 33-47. Proceedings of the workshop organized by the working committee on agricultural science and forestry. 9 September 2000. Colombo: National Science Foundation.

Phillips, B.F. \& M. Pérez-Ramírez (Eds.). 2018. Climate Change Impacts on Fisheries and Aquaculture: A Global Analysis. Volumes I and II. Oxford: Wiley-Blackwell. 992 p.

Pushpalatha, K.B.C. \& J. Chandrasoma. 2010. Culture-based fisheries in minor perennial reservoirs in Sri Lanka: variability in production, stocked species and yield implications. Journal of Applied Ichthyology 26: 99-104. https://doi.org/10.1111/j.14390426.2009.01361.x

Saaty, T.L. 1977. A scaling method for priorities in hierarchical structures. Journal of Mathematical Psychology 15: 234-281. https://doi.org/10.1016/0022-2496(77)90033-5

Sugunan, V.V. \& P.K. Katiha. 2004. Impact of stocking on yield in small reservoirs in Andhra Pradesh, India. Fisheries Management and Ecology 11: 65-69. https://doi.org/10.1046/j.13652400.2003.00370.x

Thayaparan, K. 1982. The role of seasonal tanks in the development of freshwater fisheries in Sri Lanka. Journal of Inland Fisheries (Sri Lanka) 1: 133-152.

Ulluwishewa, R. 1995. Traditional practices of inland fishery resources management in the dry zone of Sri Lanka: Implication for sustainability. Environmental Conservation 22(2): 127-133.

Wijenayake, W.M.H.K., U.A.D. Jayasinghe, U.S. Amarasinghe, J.A. Athula, K.B.C. Pushpalatha \& S.S. De Silva. 2005. Culture-based fisheries in non-perennial reservoirs in Sri Lanka: production and relative performance of stocked species. Fisheries Management and Ecology 12: 249-258.

https://doi.org/10.1111/j.1365-

2400.2005.00447.x

Wijenayake, W.M.H.K., A.B.A.K. Gunaratne, S.S. De Silva \& U.S. Amarasinghe. 2014. Use of geographical information system and remote sensing techniques for planning culture-based fisheries in non-perennial reservoirs of Sri 
W.M.H.K. Wijenayake et al.

Lanka. Lakes and Reservoirs: Research and Management 19: 183-191.

https://doi.org/10.1111//re.12071

Wijenayake, W.H.H.K., U.S. Amarasighe \& S.S. De Silva. 2016. Application of a multiplecriteria decision making approach for selecting non-perennial reservoirs for culture-based fishery development: Case study from Sri Lanka. Aquaculture 459: 26-35.

https://doi.org/10.1016/j.aquaculture.2016.03.0 19

Winfield, I.J. \& J.S. Nelson (Eds). 1991. Cyprinid Fishes: Systematics, Biology and Exploitation. Fish and Fisheries Series, London: Chapman and Hall. 667 p. https://doi.org/10.1007/97894-011-3092-9

\section{ELECTRONIC REFERENCES}

OECD/FAO. 2018. OECD-FAO agricultural outlook 2018-2027. http://www.fao.org/public ations /oecd-fao-agricultural-outlook/2018-202 7/ en/

http://www.fisheries.gov.lk/content.php?cnid=ststc https://19january2017snapshot.epa.gov/climate-

impacts/climate-impacts-agriculture-and-foodsupply_html 